\title{
TOXICIDADE DE ACARICIDAS/INSETICIDAS EMPREGADOS NA CITRICULTURA PARA A ABELHA AFRICANIZADA APIS MELLIFERA L., 1758 (HYMENOPTERA: APIDAE)
}

\section{S.M. Carvalho ${ }^{1}$, G.A. Carvalho ${ }^{1}$, C.F. Carvalho ${ }^{1}$, J.S.S. Bueno Filho ${ }^{2}$, A.P.M. Baptista ${ }^{1}$}

${ }^{1}$ Universidade Federal de Lavras, Departamento de Entomologia, CP 3037 CEP 37200-000, Lavras, MG, Brasil. E-mail:smalfitano@uol.com.br

\section{RESUMO}

Este trabalho teve como objetivo avaliar a toxicidade de produtos fitossanitários comerciais empregados em cultura de citros para abelhas Apis mellifera Linnaeus. Os bioensaios foram realizados em laboratório, sendo tomadas medidas repetidas no tempo de mortalidade para os produtos tiametoxam, deltametrina, lufenuron, tebufenozida, propargito, cihexatina, metidationa e abamectina. A exposição das abelhas aos compostos foi realizada por meio de pulverização, ingestão de alimento contaminado e contato com superfícies tratadas. Independente do modo de exposição, tiametoxam, metidationa e abamectina foram extremamente tóxicos, com $\mathrm{TL}_{50}$ médio de 3,57; 3,34 e 23,12 horas, respectivamente. O inseticida deltametrina foi pouco tóxico quando pulverizado sobre as abelhas, mas demonstrou-se bastante tóxico quando ingerido e/ou em contato com resíduos sobre superfícies. Propargito foi tóxico quando ingerido pelas abelhas, com $\mathrm{TL}_{50}$ de 64,65h; entretanto, nos demais bioensaios, assemelhou-se a cihexatina, tebufenozide e lufenuron que foram considerados como inócuos às abelhas africanizadas adultas.

PALAVRAS-CHAVE: Abelha africanizada, polinizador, toxicidade, seletividade.

\section{ABSTRACT}

TOXICITY OF ACARICIDES/INSECTICIDES FOR CITRUS CROP TO THE AFRICANIZED HONEYBEE APIS MELLIFERA L., 1758 (HYMENOPTERA: APIDAE). The purpose of this work was to evaluate the toxicity of commercial pesticides used on citrus crop to the honey bees Apis mellifera Linnaeus. The number of dead honey bees was registered during time assays, which were carried out in laboratory conditions with the chemicals thiamethoxam, deltamethrin, lufenuron, tebufenozide, propargite, cyhexatin, methidathion and abamectin. The exposure of the honey bees to the chemicals was made by spraying, food contamination and contact with contaminated surfaces. In all assays, thiamethoxam, methidathion and abamectin were highly toxic, with average lethal times $\left(\mathrm{LT}_{50}\right)$ of $3.57 ; 3.34$ and $23.12 \mathrm{~h}$, respectively. In spraying assays, deltamethrin showed low toxicity to the honey bees, however, in supplied food contamination and residue contact tests, this pyrethroid was very toxic. For propargite, medium toxicity was verified when the contaminated food was supplied to the bees, with a $\mathrm{LT}_{50}$ of $64.65 \mathrm{~h}$, and in the other assays, a similar effect to cyhexatin, tebufenozide and lufenuron was verified, with low toxicity to the adult of africanized honeybees.

KEY WORDS: Africanized honeybee, polinizator, toxicity, selectivity.

\section{INTRODUÇÃO}

Segundo MALERBO-SOUZA et al. (2004), a grande importância da manutenção de abelhas em pomares citrícolas não está relacionada somente com o sucesso da frutificação, incremento de produçãoe melhoriana qualidade do fruto, mas também com os produtos obtidos das abelhas como mel, pólen, própolis e geleia real.

Fatores como fragmentação e/ou alteração do habitat, plantio em monocultura, diminuição da oferta dealimento e/ou refúgio favorecem o declínio de populações de insetos polinizadores; entretanto, o uso de produtos fitossanitários é considerado o

${ }^{2}$ Universidade Federal de Lavras, Departamento de Ciências Exatas, Lavras, MG, Brasil. 
recurso tecnológico mais impactante para os polinizadores (KEARNS; INOUYE, 1997; DEVINE; FURLONG, 2007).

BARNETT et al. (2007) verificaram no Reino Unido, entre os anos de 1989 e 2003, que a redução populacional de abelhas estava relacionada com aplicações de inseticidas organofosforados, carbamatos e piretroides. AtKInset al. (1981) avaliaram os efeitos de 399 produtos sobre abelhas em nível de laboratório e decampo, econstataram que $20 \%$ foram extremamente tóxicos a Apis mellifera Linnaeus, 15\% moderadamente tóxicos e $65 \%$ apresentaram baixa toxicidade ou foram inócuos.

Foi observado que a grande maioria dos trabalhos toxicológicos realizados no mundo tem sido feita com espécies puras de abelhas; entretanto, segundo WHITFIELD et al. (2006), em condições brasileiras, verifica-se a existência de um híbrido africanizado oriundo do cruzamento de Apis mellifera mellifera Linnaeus x Apis mellifera scutelatta (Lepeletier, 1836), que precisa ainda ser testado quanto à sua suscetibilidade aos produtos fitossanitários, visto que alguns trabalhos têm demonstrado que abelhas africanizadas apresentam maior tolerância a produtos químicos (DANKa et al., 1994; Delaplane; MAYER, 2005).

Devidoaobaixo número deinformações a respeito dos efeitos de inseticidas / acaricidas sobre esse híbrido e a necessidade de conservação desses agentes polinizadores em pomares citrícolas, o presente trabalho teve como objetivo avaliar a ação de produtos químicos sobre adultos de $A$. mellifera em testes de pulverização, ingestão de dieta contaminada e de exposição a superfícies tratadas.

\section{MATERIALEMÉTODOS}

Para realização dos bioensaios, adultos de abelhas africanizadas foram coletados em melgueira de uma colônia do apiário da Universidade Federal de Lavras (UFLA). Usando diferentes técnicas de contaminação, as abelhas foram expostas aos produtos fitossanitários em suas maiores dosagens recomendadas pelos fabricantes para a cultura de citros (Tabela 1). As técnicas envolvidas nos experimentos foram selecionadas visando obter resultados sobre diferentes modos de exposição das abelhas aos produtos fitossanitários, isto sabendo que elas podem ocorrer por contato direto em pulverizações, caminhamento sobre superfície e ingestão de alimento contaminado (Delaplane; Mayer, 2005). Para os tratamentos tidos como controle, utilizou-se somente água destilada ou alimento puro.

Para facilitar o manuseio das abelhas durante a realização dos experimentos os insetos foram anestesiados com $\mathrm{CO}_{2}$ por 2 minutos. Os ensaios foram realizados em delineamento inteiramente casualizado, com 10 repetições para cada tratamento, sendo cada unidade experimental formada por 10 abelhas adultas, que foram mantidas em sala climatizada a $25 \pm 2{ }^{\circ} \mathrm{C}$, UR de $70 \pm 10 \%$ e fotofase de 12 horas.

\section{Pulverização dos produtos sobre A. mellifera}

Cem abelhas por tratamento, após serem anestesiadas, foram colocadas em placa de Petri e submetidas à pulverização dos produtos por meio de torre de Potter com taxa de aplicação de 1,5 $50,5 \mu \mathrm{L} /$ $\mathrm{cm}^{2}$ a $15 \mathrm{lb} / \mathrm{pol}^{2}$, em conformidade com recomendações da IOBC (HASSAN, 1994). Em seguida, foram transferidas para gaiolas de PVC $(15 \mathrm{~cm}$ de diâmetro x $10 \mathrm{~cm}$ de altura) vedadas na base com tecido de algodãobranco ena extremidade superior com tecido tipo filó. A alimentação constou de pasta Cândi(WAHL, 1968) e algodão embebido em água destilada que foram dispostos sobre o filó na parte superior da gaiola.

Tabela 1 - Ingredientes ativos, classe, formulação e dosagem dos produtos empregados nos ensaios de toxicidade a Apis mellifera.

\begin{tabular}{lllc}
\hline Ingrediente ativo & Classe & Formulação & $\begin{array}{c}\text { Concentração empregada } \\
\left.\text { (em 100 L de } \mathrm{H}_{2} \mathrm{O}\right)\end{array}$ \\
\hline tiametoxam & neonicotinoide & $250 \mathrm{WG}$ & $150 \mathrm{~g}$ \\
deltametrina & piretroide & $25 \mathrm{EC}$ & $50 \mathrm{~mL}$ \\
lufenurom & benzoilureia & $\mathrm{EC}$ & $75 \mathrm{~mL}$ \\
tebufenozida & diacilhidrazina & $240 \mathrm{CS}$ & $50 \mathrm{~mL}$ \\
propargito & sulfito de alquila & $720 \mathrm{EC}$ & $100 \mathrm{~mL}$ \\
cihexatina & organoestânico & $500 \mathrm{CS}$ & $50 \mathrm{~mL}$ \\
metidationa & organofosforado & $400 \mathrm{EC}$ & $125 \mathrm{~mL}$ \\
abamectina & avermectina & $18 \mathrm{EC}$ & $30 \mathrm{~mL}$ \\
\hline
\end{tabular}


Fornecimento de pasta Cândi contaminada com os produtos a $A$. mellifera

A pasta Cândi foi preparada com $50 \mathrm{~g}$ de açúcar de confeiteiro e $10 \mathrm{~mL}$ de mel, sendo que a quantidade de produto fitossanitárioa serincorporada foi determinada em função do volume da dieta e da dosagem préestabelecida. Após distribuição das abelhas em númerode10 por gaiola dePVC, a pasta Cândi contaminada por cada um dos produtos fitossanitários foi disposta sobreo filóna partesuperior da gaiola,juntamentecom algodão embebido em água destilada.

Efeito residual dos produtos fitossanitários sobre A. mellifera

Para realização desses experimentos, foram confeccionadas arenas cilíndricas usando placas de Petri de $10 \mathrm{~cm}$ diâmetro $\mathrm{x} 2 \mathrm{~cm}$ altura dispostas uma sobre a outra de forma invertida e fixadas lateralmente por quatro grampos metálicos em formato de " $h$ ". Esses grampos foram colocados diametralmente opostos e equidistantes sobre a borda das placas, dando sustentação ao conjunto e também permitindo um espaçamento de 2,5 mm entre as placas, propiciando aeração e eliminação de possíveis vapores tóxicos formados. O cilindro formado pela junção das duas placas, apresentou um volume médio de $333,6 \mathrm{~cm}^{3}$.

\section{Contato de $A$. mellifera com superfície de vidro contaminada}

Antes da montagem das arenas, as superfícies internas das placas de Petri foram pulverizadas com os produtos fitossanitários por meio de torre de Potter, com taxa de aplicação de $1,5 \pm 0,5 \mu \mathrm{L} / \mathrm{cm}^{2}$ a $15 \mathrm{lb} / \mathrm{pol}^{2}$. Após a evaporação do excesso de calda química, colocou-se o alimento acondicionado em uma tampa plástica de $2 \mathrm{~cm}$ de diâmetro e, em seguida, introduziramse as abelhas anestesiadas no interior das arenas.

\section{Contato de $A$. mellifera com folhas de citros conta- minadas}

Folhas detangerina Ponkan Citrus reticulata Blanco, coletadas em uma planta isenta de tratamento fitossanitário, foram imersas por 5 segundos nas caldas químicas de cada tratamento. Essa técnica foi empregada com o objetivo de se ter o produto fitossanitário a ser testado distribuído de forma homogenia na superfície foliar. Para retirar o excesso deágua, as folhas ficaram em repouso por aproximadamente 3 horas em local arejado e à sombra.

Após secagem,em cada arena, quatrofolhas tratadas (duas na parte superior e duas na inferior) foram fixadas pela face abaxial mediante fita adesiva de dupla face, tendo sido o alimento acondicionado em uma tampa plástica colocadanabasedaarena, ondeseintroduziram, também, as abelhas previamente anestesiadas.

\section{Análise dos dados obtidos}

Em todos os ensaios os horários de avaliação foram padronizados, finalizando quando a mortalidade do tratamento controle fosse igual ou superior a 20\% (EPA-OPPTs, 1996). As avaliações foram feitas a 1 , $2,3,4,5,6,9,12,15,18,21,24,30,36,42,48,60$ e 72 horas. Durante as avaliações, registraram-se o número de espécimes mortos em cada gaiola, sendo considerados como tal aqueles que não respondiam a estímulos mecânicos.

Os ensaios foram realizados em DIC eem esquema fatorial (9 tratamentos $x 4$ técnicas de aplicação), com medidas repetidas no tempo, sendo que os dados obtidos foram submetidos à análise de sobrevivência usando o pacote Survival (THERnEAu; LuMLEY, 2008) compilado pelo software $\mathrm{R}^{\circledR}$ (2008). A escolha dos modelos foi baseada na análise de resíduos, usando a distribuição de Weibull por permitir ajuste apropriado(SGriLO, 1982). De posse dos modelos, realizou-se um teste de contraste para verificar a semelhança entre os tratamentos, criando-se grupos de produtos fitossanitários com efeitos semelhantes. Também se calculou os respectivos tempos letais $50\left(\mathrm{TL}_{50}\right)$ (Moncharmont et al., 2003; Colosimo; Giolo, 2006).

\section{RESULTADOSEDISCUSSÃO}

Efeitos dos produtos em pulverização sobre $A$. mellifera

Uma hora após a pulverização, tiametoxam e metidationa causaram mortalidade de $71 \%$ e $68 \%$ das abelhas, respectivamente, enovehoras após, provocaram a mortede $100 \%$ dos adultos. Duranteas primeiras horas foi possívelobservar queas abelhas tratadas com esses produtos apresentaram distúrbios de coordenação motora, incapacidade de voo e prostração; porém, tiametoxam foi mais tóxico em um menor espaço de tempo, com $\mathrm{TL}_{50}$ de 1,7 horas e metidationa de 2,62 horas. Alta toxicidade também foi observada para abamectina que matou 99\% das abelhas 30 horas após a sua contaminação, com $\mathrm{TL}_{50}$ de 13,04 horas (Fig. 1).

Cihexatina, deltametrina, lufenurom e propargito apresentaram baixa toxicidadee $\mathrm{TL}_{50}$ de 178,57 horas. Deltametrina induziu o efeito knockdown fazendo com que os insetos ficassem no fundo das gaiolas com movimentos desordenados e trêmulos, durante o período de uma hora, findo o qual, voltaram ao normal. A maior taxa de sobrevivência foi observada no tratamento à base de tebufenozida (Fig. 1). 


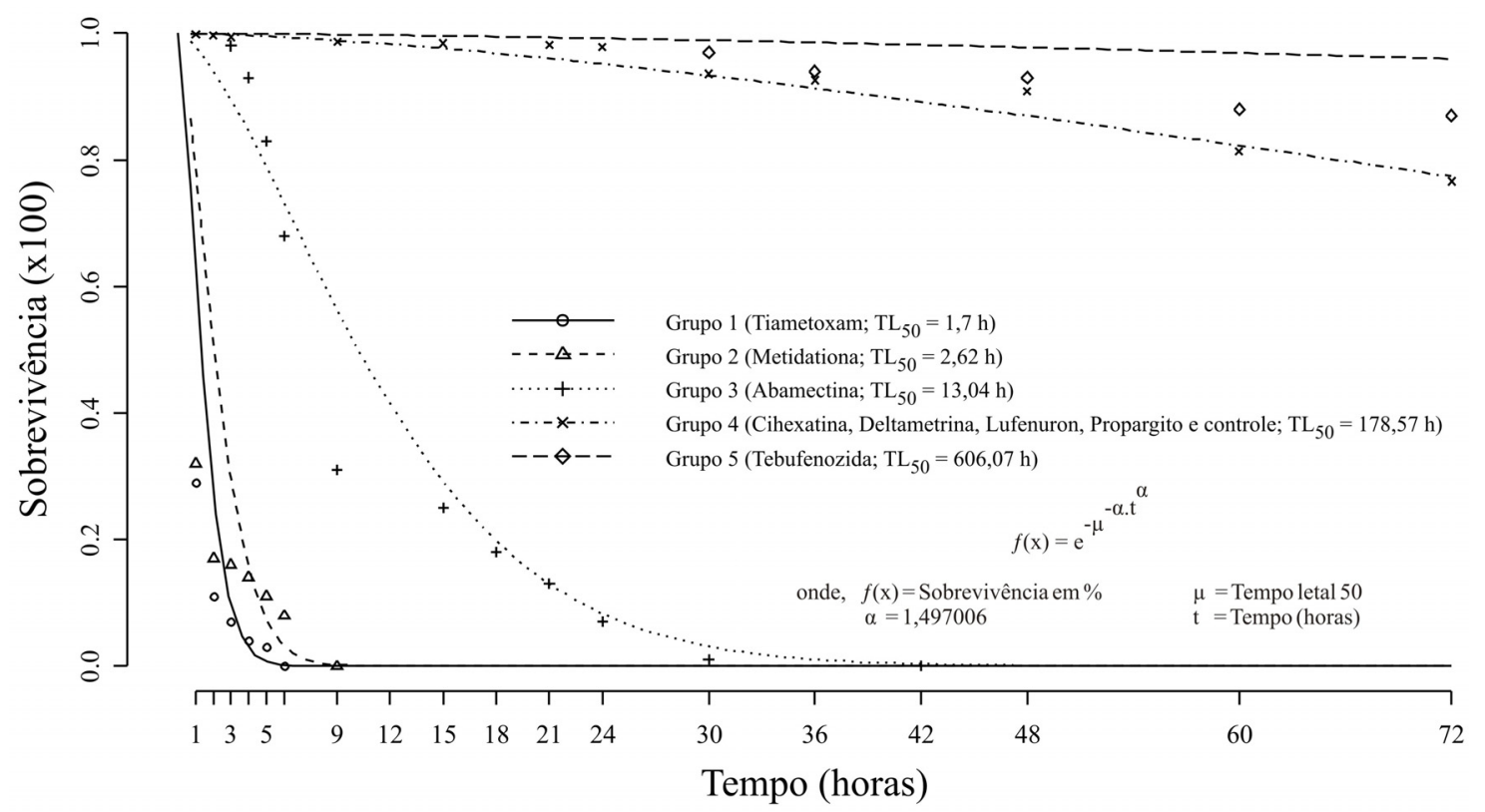

Fig. 1 - Sobrevivência (\%) de operárias de Apis mellifera após pulverização dos produtos fitossanitários, tempos letais $\left(\mathrm{TL}_{50}\right)$ em horas.

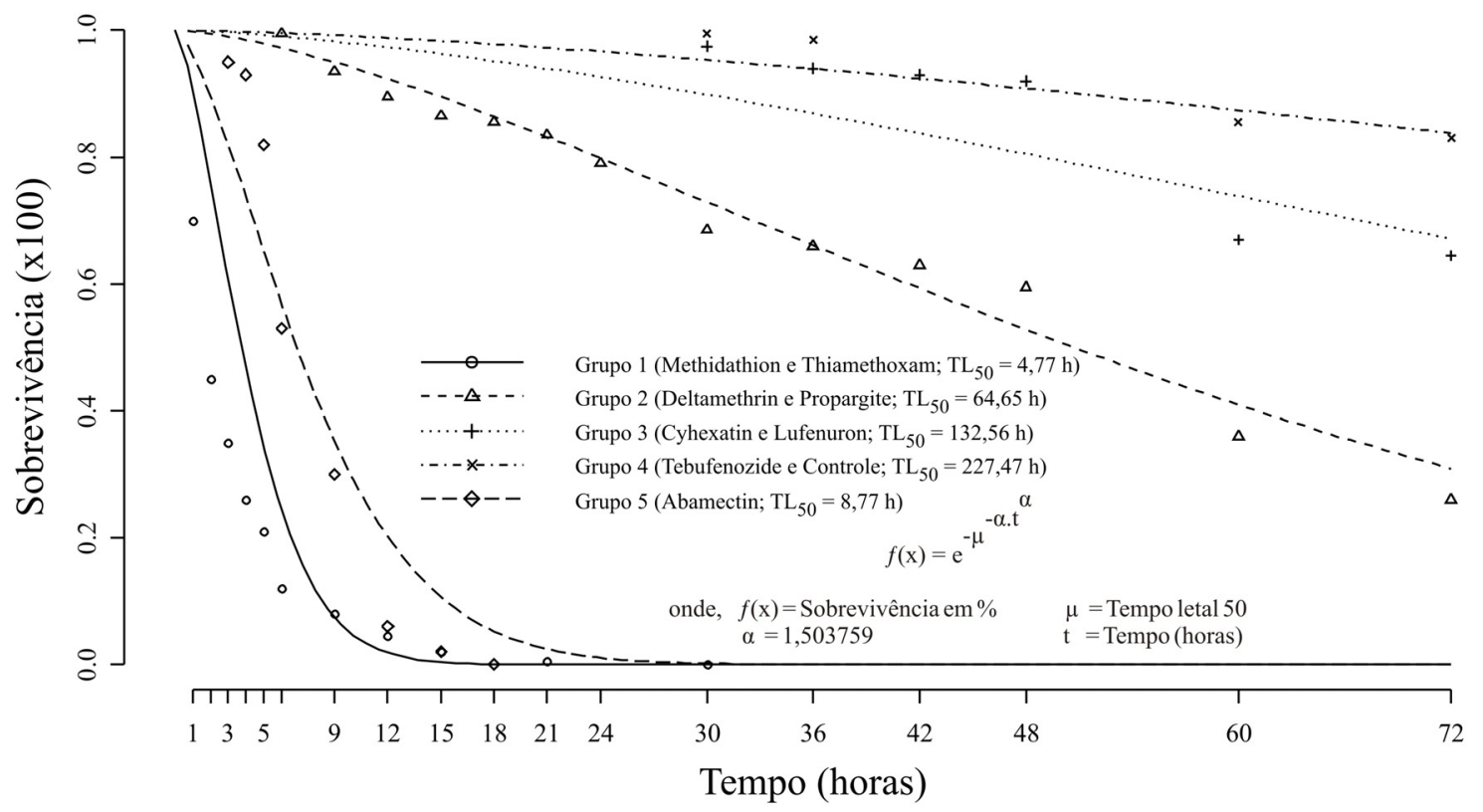

Fig. 2 - Sobrevivência (\%) de operárias de Apis mellifera após fornecimento de pasta Cândi contaminada com os produtos fitossanitários, tempos letais $\left(\mathrm{TL}_{50}\right)$ em horas.

Efeitos dos produtos quando fornecidos em pasta Cândi contaminada sobre $A$. mellifera

Trinta minutos após o fornecimento do alimento contaminado às abelhas, e possivelmente com baixa ingestão de dieta, tiametoxam e metidationa foram tóxicos às abelhas, provocando tremores, falta de coordenação motora e prostração, fazendo com que elas permanecessem no fundo da gaiola. Uma hora após o início do ensaio, tiametoxam provocou mortalidade de $46 \%$ das abelhas; seis horas após apresentou média de $89 \%$ e 24 horas após causou $99 \%$ de mortalidade. O inseticida metidationa também foi tóxico logo nas primeiras horas após o fornecimento da pasta Cândi contaminada, causando mortalidade de $14 \%$ na primeira hora, de $87 \%$ na sexta e de $100 \%$ na décima quinta hora. Para esses dois compostos a $\mathrm{TL}_{50}$ foi de 4,77 horas, demonstrando a alta toxicidade por meio de ingestão (Fig. 2). 


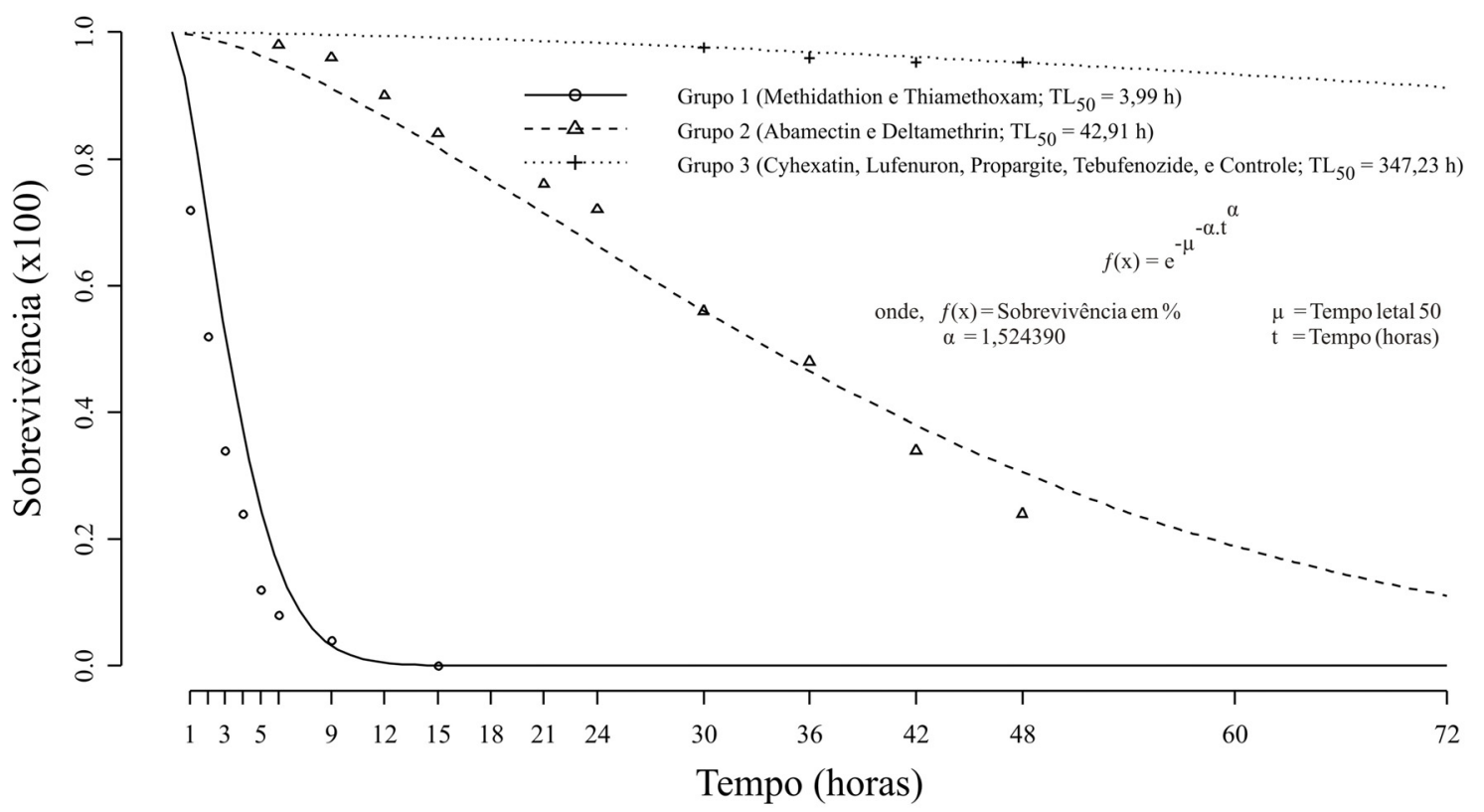

Fig. 3 - Sobrevivência (\%) de operárias de Apis mellifera após o contato com superfície de vidro contaminadas com os produtos fitossanitários, tempos letais $\left(\mathrm{TL}_{50}\right)$ em horas.

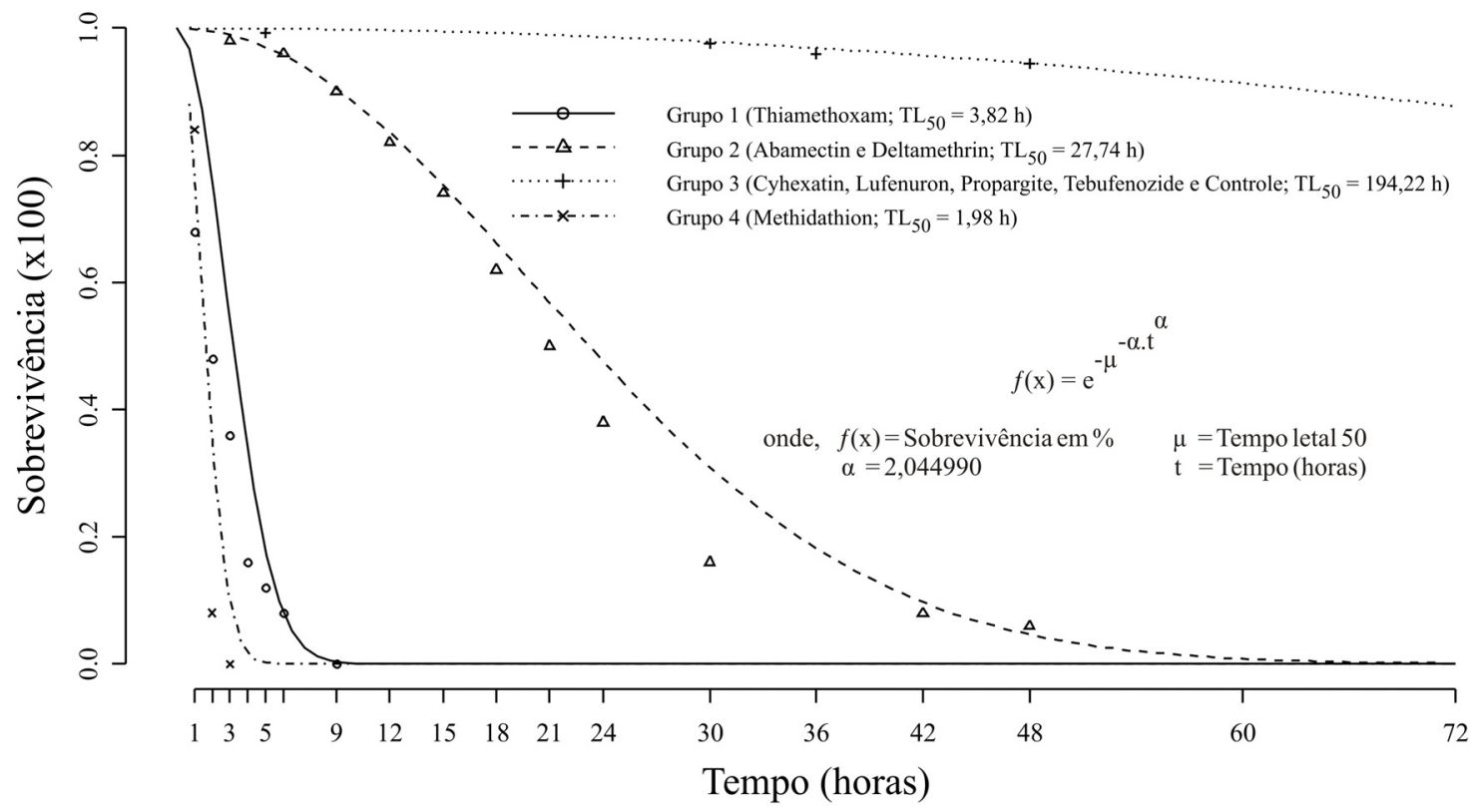

Fig. 4 - Sobrevivência (\%) de operárias de Apis mellifera após o contato com folhas de citros contaminadas com os produtos fitossanitários, tempos letais $\left(\mathrm{TL}_{50}\right)$ em horas.

O acaricida abamectina foi extremamente tóxico às abelhas via ingestão, principalmente em comparação ao ensaio de pulverização, demonstrando um risco maior de intoxicação para abelhas ao consumirem alimento contaminado com esse composto. Após cinco horas do fornecimento da dieta contaminada, causou mortalidade de $18 \%$, chegando a $100 \%$ na avaliação de 18 horas, com $\mathrm{TL}_{50}$ de 8,77 horas. Deltametrina e propargito provocaram mortalidade crescente ao longo das avaliações, alcançando médi- as finais de mortalidade às 72 horas da ordem de $67 \%$ e $75 \%$, respectivamente e $\mathrm{TL}_{50}$ de 64,65 horas (Fig. 2).

$\mathrm{O}$ acaricida cihexatina e o inseticida lufenurom provocaram mortalidade moderada, com médias de $31 \%$ e $40 \%$, respectivamente, ao final das avaliações (72h) e TL Te $_{50}$ d32,56 horas (Fig. 2). Como observado no ensaio de pulverização, tebufenozida foi novamente o menos tóxico, igualando-se ao tratamento controle, com mortalidade na última avaliação de

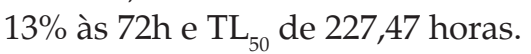




\section{Efeitos do contato de abelhas com superfícies de vidro contaminadas com os produtos}

Tiametoxam e metidationa foram extremamente tóxicos às abelhas, sendo que, na avaliação de $1 \mathrm{~h}$, tiametoxam provocou mortalidade de $56 \%$ das abelhas e metidationa foi inofensiva. Entretanto, 4 h após oinício do experimento, verificou-se que esses produtos provocaram mortalidade de $76 \%$ das abelhas. A morte total dos insetos foi observada na avaliação de seis horas para metidationa e de 15 horas para tiametoxam, que apresentaram $\mathrm{TL}_{50}$ médio de 4,0 horas (Fig. 3).

Abamectina edeltametrina também foram tóxicos, apresentando o $\mathrm{TL}_{50}$ de 42,91 horas. Deltametrina causou efeito knockdown, sendo que as abelhas permaneceram nessa condição durante grande parte do bioensaio, com mortalidade final de 64\% (48h). Abamectina não provocou efeito comportamental atípico, apresentando média de mortalidade às 48 horas de $88 \%$. Os produtos cihexatina, lufenurom, propargito e tebufenozida foram inócuos às abelhas, com mortalidade média de $4,8 \%$ e $\mathrm{TL}_{50}$ médio de 347,23 horas (Fig. 3).

\section{Efeitos do contato de abelhas com folhas de citros contaminadas com os produtos}

Tiametoxam provocou a morte de todas as abelhas nove horas após entrarem em contato com os seus resíduos e apresentou $\mathrm{TL}_{50}$ de 3,82 horas. Metidationa provocou a morte de $100 \%$ das abelhas nas três primeiras horas após o contato dos insetos com as folhas contaminadas, com $\mathrm{TL}_{50}$ de 1,98 horas. Os compostos abamectina e deltametrina foram tóxicos às abelhas, apresentando mortalidades de $88 \%$ e $100 \%$, respectivamente e com $\mathrm{TL}_{50}$ médio de 27,74 horas (Fig. 4). O piretroide deltametrina provocou efeito knock down das abelhase, posteriormente, a sua morte. Os demais produtos, cihexatina, lufenurom, propargito e tebufenozida não foram tóxicos às abelhas, com mortalidade média de 5,6\% e TL Te $_{50}$ 194,22 horas (Fig. 4).

Independente do modo de exposição, tiametoxam mostrou-se extremamente tóxico às abelhas, confir-mandos resultados obtidos por Antunes-Kenyon; Kennedy (2001), os quais constataram que resíduos foliares desse inseticida $(100,82$ g i.a./ha) foram altamente tóxicos para abelhas, provocando mortalidade superior a $80 \%$ aos três dias de sua aplicação. IwASA et al. (2004) verificaram que o neonicotinoide tiametoxam, o qual apresenta um agrupamento nitro, faz com que essa molécula seja em média 192 vezes mais tóxica às abelhas que aquelas que possuem o agrupamento ciano como o acetamiprid.
Em todos os bioensaios o produto metidationa foi extremamente tóxico às abelhas, causando $100 \%$ de mortalidade nas primeiras horas. JOHANSEN (1977), AtKins et al. (1981), PORRINi et al. (2003) e Delaplane; Mayer, 2005 também verificaram a toxicidade desse produto, classificando-o como extremamente tóxico para as abelhas em ensaios de laboratório e campo, recomendando que seu uso não seja feito antes e durante o período de florescimento.

A mortalidade de abelhas provocada pela deltametrina também foi relatada por AtKINs et al. (1981), que a consideraram como altamente tóxica em laboratório e áreas citrícolas. TASEI; DiNET (1981) concluíram que deltametrina foi tóxica para abelhas solitárias Megachile rotundata Fabricius, 1787 tanto em teste de pulverização direta como em contato com superfícies contaminadas, papel filtro e folhas de Melilotus albus Medik, provocando o efeito knock down. VANDAME et al. (1995) e BelzUNCES et al. (2001) verificaram que dosagens subletais desse piretroide provocaram efeitos adversos sobre abelhas, como alteração no voo de retorno à colônia e hipotermia. Resíduos de deltametrina em folhas de trigo (UNAL; JEPSON, 1991) também foram tóxicos aos predadores Bembidion lampros (Herbst, 1784) e Coccinella septempunctata (Linnaeus, 1758). CILGI; JEPSON (1995) relataram que a toxicidade de deltametrina em folhas está não somente associada a molécula, mas também a interação dessa com as folhas, principalmente pela cera presente nas camadas da epiderme. O efeito repulsivo, além da menor capacidade de detoxificação de $M$. rotundata a deltametrina, também foi destacado por TASEI; DinET (1981). Segundo RIETH; LEVIN (1987), o contato prolongado de abelhas com resíduos de deltametrina pode "agravar" o seu efeito tóxico, o que pode ter contribuído para os resultados obtidos no presente trabalho quando em contato em superfícies contaminadas.

Os resultados obtidos com abamectina assemelham-se aos descritos por AtKINSet al. (1981), WisLOCKI et al. (1989), ToMLIn (1994) e WANG et al. (2006), que a consideraram como altamente tóxica a abelhas em casos de pulverização direta e ingestão de alimento contaminado. Exceto no ensaio de contaminação do alimento, no qual propargito foi mediamente tóxico, constatou-se o que foi relatado por diversos pesquisadores, sendo classificado como não tóxico as abelhas (JoHANSEN, 1977; DeVILlers, 2002; DeVILlers et al., 2003; MARLETTO et al.,2003). A maior toxicidade do acaricida propargito pode estar relacionada à característica corrosiva do composto citotóxico, podendo ocasionar irritações dérmicas ou em tecidos, como no caso o sistema digestivo da abelha (O'MALLEY, 2001) ou em outra hipótese atuar na fosforilação oxidativa inibindo a síntese de ATP (TomLIN, 1994). No caso de 
cihexatina, a baixa toxicidade a esses polinizadores, encontrada no presente trabalho, confirma resultados de Hunter (1976), Johansen (1977), AtKins et al. (1981), Sekita; Yamada (1993) e Devillers (2002). Cihexatina atua diretamente na síntese de ATP, inibindo a ação da ATP sintetase, sendo tóxica a diversos ácaros fitofagos, mas não a predadores e insetos benéficos (STENERSEN, 2004).

Resultados de inocuidade do inseticida regulador de crescimento tebufenozida para abelhas adultas observado nesse estudo, assemelham-se àqueles descritos por DHADIALLa et al. (1998), sendo que esse composto atua como antagonista do hornômio de muda ecdisônio, responsável pela regulação do processo de crescimento do inseto durante a fase jovem. Em adultos, esse hormônio atua como mediador no processo reprodutivo de insetos, contudo, em abelhas adultas verifica-se somente a ocorrência de uma fêmea funcional (rainha) e operárias (fêmeas onde o aparelho reprodutor não desenvolveu-se). MOMMAERTs et al. (2006a) recomendaram o uso de tebufenozida pelo fato desse inseticida não apresentar efeito adverso a adultos de Bombus terrestris (Linnaeus, 1758). NaKagaWA; Matsumura (1994) e HAJJAR; CASIDA et al. (1978) descreveram o mecanismo deação dolufenuron como sendo um potenteinibidor da síntese de quitina, atuando em fases jovens de insetos, sendo que sua ação pode estar relacionada com o estágio de polimerização ou no transporte dos precursores da quitina. Com relação ao lufenuron, TASEI (2001) constatou que esse composto inibiu a formação da glândula hipofaringeal, diminuiu a capacidade de oviposição e provocou morte de larvas de abelhas. Em estudos com mamangavas, MOMMAERTS et al. (2006b) não verificaram mortalidade de adultos, mas sim delarvas, ovos e má formação da cutícula.

\section{CONCLUSÕES}

Independente do modo de exposição avaliado, tiametoxam, metidationa e abamectina foram extremamente tóxicos para adultos de Apis mellifera.

Deltametrina foi tóxica às abelhas quando em contato com superfícies contaminadase/ou ingerida, e menos tóxica quando aplicada diretamente sobreos insetos.

Propargito foi tóxico quando oferecido às abelhas A. mellifera via pasta Cândi contaminada, e nas demais técnicas avaliadas apresentou baixa toxicidade.

Cihexatina, lufenuron e tebufenozida foram inofensivos aos adultos de $A$. mellifera, sendo necessária a avaliação de seus possíveis efeitos em fases jovens para posterior utilização em programas de manejo integrado de pragas da cultura de citros.

\section{AGRADECIMENTO}

Ao Conselho Nacional de Desenvolvimento Científico e Tecnológico-CNPq, pela concessão de bolsa de estudos ao primeiro autor.

\section{REFERÊNCIAS}

ANTUNES-KENYON, S.E.; KENNEDY, G. Thiamethoxam - A new active ingredient review. Massachusetts: Massachusetts Pesticide Bureau, 2001. 37p.

ATKINS, E.L.; KELLUM, D.; ATKINS, K.W. Reducing pesticides hazardous to honeybees - Mortality prediction techniques and integrated management strategies. Berkeley: University of California, 1981. 20p.

BARNETT, E.A.; CHARLTON, A.J.; FLETCHER, M.R. Incidents of bee poisoning with pesticides in the United Kingdom, 1994-2003. Pest Management Science, v.63, p.1051-1057, 2007.

BELZUNCES, L.P.; VANDAME, R.; XINGFA, G.U. Joint effects of pyrethroid insecticides and azole fungicides on honey-bee thermoregulation. In: BELZUNCES, L.P.; PELISSIER, C.; LEWIS, G.B. (Ed.). Hazard of pesticides to bee. Avignon: INRA, 2001. p.297-298.

CILGI, T.; JEPSON, P.C. The risk posed by deltamethrin drift to hedgerow butterflies. Environmental Pollution, v.87, p.1-9, 1995.

COLOSIMO, E.A.; GIOLO, S. R. Análise de sobrevivência aplicada. São Paulo: Edgar Blucher, 2006. 392p.

DANKA, R.G.; LOPER, G.M.; VILLA, J.D.; WILLIAMS, J.L.; SUGDEN, E.A.; COLLINS, A.M.; RINDERER, T.E. Abating feral africanized honey bees (Apis mellifera L.) to enhance mating control of European queens. Apidologie, v.25, p.520-529, 1994.

DELAPLANE, K.S.; MAYER, D.F. Crop pollination by bees. Oxon: CABI Publishing, 2005. 344p.

DEVILLERS, J. Acute toxicity of pesticides to honey bees. In: DEVILLERS, J.; PHAM-DELEGUE, M.H. (Ed.). Honey bees: estimating the environmental impact of chemicals. London: Taylor \& Francis, 2002. p.56-66.

DEVILLERS, J.; DECOURTYE, A.; BUDZINSKI, H.; PHAM-DELĖGUE, M.H.; CLUZEAU, S.; MAURIN, G. Comparative toxicity and hazards of pesticides to Apis and non-Apis bees. A chemometrical study. SAR and QSAR in Environmental Research, v.14, p.389-403, 2003.

DEVINE, G.J.; FURLONG, M.J. Insecticide use: contexts and ecological consequences. Agriculture and Human Values, v.24, p.281-306, 2007. 
DHADIALLA, T.S.; CARLSON, G.R.; LE, D.P. New insecticides with ecdysteroidal and juvenile hormone activity. Annual Review of Entomology, v.43, p.545-569, 1998.

HAJJAR, N.P.; CASIDA, J.E. Insecticidal benzoylphenyl urea: structure activity relationships as chitin synthesis inhibitors. Science, v.200, p1499-1500, 1978.

HASSAN, S.A. Activities of the IOBC/WPRS working group "Pesticides and beneficial organisms". IOBC/ WPRS Bulletin, v.17, p.1-5, 1994.

HUNTER, R.C. Organotin compounds and their use for insect and mite control. Environmental Health Perpectives, v.14, p.47-50, 1976.

IWASA, T.; MOTOYAMA, N.; AMBROSE, J.T.; ROE, R.M. Mechanism for the differential toxicity of neonicotinoid insecticides in the honey bee, Apis mellifera. Crop Protection, v.23, p.371-378, 2004.

JOHANSEN, C.A. Pesticides and Pollinators. Annual Review of Entomology, v.22, p.177-192, 1977.

KEARNS, C.A.; INOUYE, D.W. Pollinators, flowering plants and conservation biology. BioScience, v.47, p.297-307, 1997.

MALERBO-SOUZA, D.T.;NOGUEIRA-COUTO,R.H.; COUTO, L.A. Honey bee attractants and pollination in sweet orange, Citrus sinensis (L.) Osbeck, var. Pera-Rio. Journal of Venomous Animals and Toxins including Tropical Diseases, v.10, p.144-153, 2004.

MARLETTO, F.; PATETTA, A.; MANINO, A.

Laboratory assessment of pesticide toxicity to bumblebees. Bulletin of Insectology, v.56, p.155-158, 2003.

MONCHARMONT, F.X.D; DECOURTYE, A; HANTIER, C.H; PONS, O.; PHAM-DELEGUE, M. Statistical analysis of honeybee survival after chronic exposure to insecticides. Environmental Toxicology and Chemistry, v.22, p.3088-3094, 2003.

MOMMAERTS, V.; STERK, G.; SMAGGHE, G. Bumblebees can be used in combination with juvenile hormone analogues and ecdysone agonists. Ecotoxicology, v.15, p.513-521, 2006a.

MOMMAERTS, V.; STERK, G.; SMAGGHE, G. Hazards and uptake of chitin synthesis inhibitors in bumblebees Bombus terrestris. Pest Management Science, v.62, p.752-758, 2006b.

NAKAGAWA, Y.; MATSUMURA, F. Diflubenzuron affects gamma-thioGTP stimulated $\mathrm{Ca}^{2+}$ transport in vitro in intracellular vesicles from the integument of the newly molted American cockroach, Periplaneta americana L. Insect Biochemistry and Molecular Biology, v.24, p.1009-1015, 1994.
O'MALLEY, M. Regulatory evaluation of the skin effects of pesticides. In: KRIEGER, R.I.; ATALA, A.; LANZA, R.P. (Ed.). 2nd.ed. Handbook of pesticide toxicology. New York: Academic Press, 2001. p.299-333.

PORRINI, C.; SABATINI, A.G.; GIROTTI, S.; GHINI, S.; MEDRZYCKI, P.; GRILLENZONI, F.; BORTOLOTTI, L.; GATTAVECCHIA, E.; CELLI, G. Honey bees and bee products as monitors of the environmental contamination. Apiacta, v.38, p.63-70, 2003.

R DEVELOPMENT CORE TEAM. R: A language and environment for statistical computing. R Foundation for Statistical Computing, Vienna, Austria. ISBN 3900051-07-0, URL Disponível em: <http:/ /www.Rproject.org>. Acesso em: 2008.

RIETH, J.P.; LEVIN, M.D. The pyrethroid insecticide hazard to honey bees. American Bee Journal, v.127, p.789, 1987.

SEKITA, N.; YAMADA, M. Use of Osmia cornifrons for pollination of apples in Aomori Prefecture, Japan. Japan Agricultural Research Quartely, v.26, p.264-270, 1993.

SGRILO, R.B. A distribuição de Weibull como modelo de sobrevivência de insetos. Ecossistema, v.7, p.9-13, 1982.

STENERSEN, J. Chemical pesticides: Mode of action and toxicology. CRC Press: Boca Raton, 2004. 296p.

TASEI, J.N.; DINET, P. Effets comparés de deux pyréthrinoides de synthèse et de trois insecticides organophosphorés sur les mégachiles (Megachile rotundata F. = pacifica Pz.). Apidologie, v.12, p.363-376, 1981.

TASEI, J.N. Effects of insect growth regulators on honey bees and non-Apis bees. A review. Apidologie, v.32, p.527-545, 2001.

THERNEAU, T.; LUMLEY, T. Survival analysis, including penalised likelihood. Package version 2.43-1, 78p. 2008.

TOMLIN, C. The pesticide manual - incorporating the agrochemicals handbook. Surrey: British Crop Protection Council, 1994. 1341p.

UNAL, G.; JEPSON, P.C. The toxicity of aphicide residues to beneficial invertebrates in cereal crops. Annals of Applied Biology, v.118, p.493-502, 1991.

VANDAME, R.; MELED, M.; COLIN, M.E.; BELZUNCES, L.P. Alteration of the homing-flight in the honey bee Apis mellifera L. exposed to sublethal dose of deltamethrin. Environmental Toxicology and Chemistry, v.14, p.855-60, 1995.

WAHL, O. Le nourrissement. In: CHAUVIN, R. (Ed.). Traité de bologie de l'Abeille. Paris: Masson et $\mathrm{C}^{\mathrm{ie}}, 1968$. Tome IV, p.162-180. 
WANG, C.J; QIU, L.H.; ZHENG, M.Q.; TAO, C.J.; JIAHG, H.; ZHANG, W.J.; LI, X.F. Safety evaluation of abamectin and its mixtures to honey bees (Apis mellifera). Journal of Agro-Environment Science, v.25, p.229-231, 2006.

WHITFIELD, C.W.; BEHURA, S.K.; BERLOCHER, S.H.; CLARK, A.G.; JOHNSTON, S.J.; SHEPPARD, W.S.;

SMITH, D.R.; SUAREZ, A.V.; WEAVER, D.; TSUTSUI,

N.D. Thrice out of Africa: Ancient and recent expansions of the honey bee, Apis mellifera. Science, v.314, p.642-645, 2006

WISLOCKI, P.G.; GROSSO, L.S.; DYBAS, R.A. Environmental aspect of abamectin use in crop protection. In: CAMPBELL, W. (Ed.). Ivermectin and abamectin, New York: Springer-Verlag, 1989. p.182-200.

Recebido em $2 / 10 / 08$

Aceito em 29/10/09 
